\title{
GASP! The crazy world of tobacco
}

\author{
Philip Boys
}

$=$

5

$\cdot$

$-5$

$\therefore 3$

$\div$

$-$

$-$

$=-$

3

$+$

.

to

7.

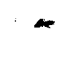

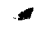

$\pm$

$=4$

$+\infty$

$\therefore$

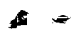

$+a$

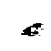

$: 5$

i.

2

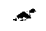

4.

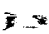

$+$

$x$

Comic Company, London SW12 8LW, UK
When comic artist Graham Higgins mentioned in passing that he had decided to quit smoking, I gave thanks. First, because he wanted to give up. Second, because I knew we could turn his decision and his skills to wider advantage.

That very week, Corinne Pearlman and I had started to work up ideas for GASP!, a comic magazine Comic Company had been commissioned to produce for Smokebusters UK, with funding from the Health Education Authority. (Corinne is Comic Company's Art Director, I am its Editorial Director.) Graham's resolution gave me the idea for a visual feature that would work without the need for a single word.

We commissioned Graham to visualise how much better streetlife would be if nobody smoked, and to render it in what he calls his over-the-top "big nose" style. The artwork on the cover of this issue of Tobacco Control shows what he came up with.

Spot the difference invokes the popular children's puzzle where two superficially identical images turn out to be very slightly different. In Graham's version, of course, it's nothing of the sort - the changes could scarcely be less subtle. Above, tobacco rules: the city is dirty, dull, and dangerous. In Nosmokia, however, streetlife is paradise. The air is clear, colours more vivid, trees flourish, window boxes burst into bloom, fit and healthy people beam all over their faces, an epidemic of Love has broken out.

Yes, it's absurd and corny, but it's also crazy and immediately comprehensible to children of all ages (and most countries). Blown up to billboard proportions, it might even beat the tobacco manufacturers at their own game!

\section{Comics in education}

Comic Company, as our name implies, specialises in intensely graphical and in most cases pretty jocular approaches to potentially quite difficult subject matters. Nearly all of our work has been in the health field, including resources dealing with HIV/AIDS, menstrual periods, and skin cancer.

Our work stems from a firm belief in the power of the cartoon and the comic strip to inform, entertain and educate. To this end we have developed the comic art vocabulary, using a wide range of artists, to respond flexibly and simply to the demands made by sensitive issues in the real world.

The overall brief for GASP! certainly had its challenges. Smokebusters, with its nearly 100000 members aged between about 8 and 14 years, has national co-ordinators but is essentially local in character - groups of various sizes from less than 100 to many thousands exist throughout the United Kingdom. This meant that GASP! would have to be sent by mail to every child individually, limiting its size to whatever could be carried for the cost of the basic-rate stamp - a maximum sheet-size of $42 \mathrm{~cm} \times 60 \mathrm{~cm}(\mathrm{~A} 2)$.

Members, moreover, were of very different ages (and, presumably, levels of literacy). Children would have to be able to read GASP! for themselves without the presence of a teacher.

We knew how we could make the material serious-yet-humorous, but there was still a problem of content. There is no lack of things to say about smoking, just a question of how to shape it in a way that is fresh and interesting. Young people easily become tired of hearing about how they personally will suffer if they smoke.

We decided that we should therefore try to appeal to a wider - in a sense, more selfless concern. We would remind readers that smoking is indeed a personal health issue, but it is also an environmental issue, and a development issue too.

On the front page of the GASP! comic, David Simpson (now the news editor of Tobacco Control) introduced the global theme: how tobacco manufacturers in the rich world - increasingly deprived of markets at home because fewer people are taking up smoking and more are giving up - are now targeting young people in developing countries with illusory claims that smoking global brands is a symbol of wealth and modernity. He also discussed the environmental, economic and other problems brought about by the spread of tobacco as a cash crop throughout the developing world.

These themes were taken up in more detail in The crazy world of tobacco, an $\mathrm{A} 2$ poster formed by unfolding the A4-sized magazine. I researched and wrote the copy, Corinne designed and illustrated it. The crazy world locates the world's largest tobacco manufacturers and growers on a map of the world seen within an ashtray, which underlines the grubbiness of the trade. All around, vignettes and brief captions illustrate an aspect of the history and global spread of tobacco, and the harm that it causes (figure 1). In this way, a huge amount of information was condensed into bite-sized chunks that would also support school students' writing projects on tobacco. 


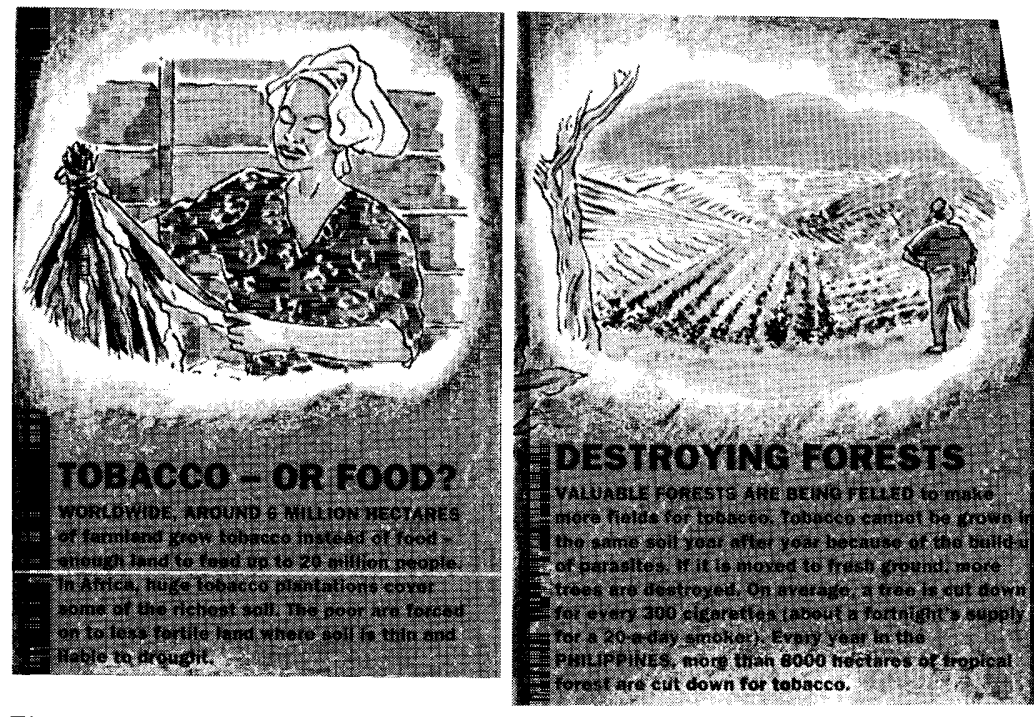

Figure 1 Two vignettes from The crazy world of tobacco

Where is "the environment"?

Many young people are understandably concerned about "nature" and "the environment". But where exactly are they? Is the environment only "outside" people - as in polluted seas and rivers or forests? What about the pollution that surrounds organs, tissues and cells?

We came to feel we could more usefully conceptualise the environment on a series of different scales, from the microcosm to macrocosm, via intimate face-to-face relations, family and friendship in home and school, as well as the city streets in which children spend much of their lives. The friends-and-family scale of things was covered in the form of an article, No problem? (figure 2), featuring advice from a number of prominent "Agony Aunts and Uncles" - writers who advise readers on their everyday problems. This came about in direct response to the readership profile. As members of Smokebusters, they would be actively anti-smoking non-smokers. We didn't want to preach to the converted, so what were their concerns? We asked the "problem page" people and they told us that they frequently received letters from non-smokers worrying on behalf of others. The article is accompanied by two cartoons by Woodrow Phoenix, a comic artist with a long list of credits including Batman and Sonic the Hedgehog.

Finally, we came down to the physiological or chemical level. Every breath you take... (the title of a well-known pop song) functions as a word square in which 80 of the 4000 or so chemicals found in cigarette smoke can be located and ticked off on a list (figure 2). Some of the "messages" are explicit - a caption tells the reader that many of these chemicals are poisonous or are known to cause cancer, that some are radioactive, and that smoke affects non-smokers as well as smokers.

The image works at a subliminal level too. For example, few of the words will be in any way comprehensible, and many are extremely long. If you can't even pronounce words such as methylnitrosoaminopyridybutanone and $n$ nitrosodiethanolamine, what effects might they be having on your body?

There are implicit visual messages, too, which cartoons and comics can convey more effectively perhaps than any other medium. The names of the chemicals form a dense cloud
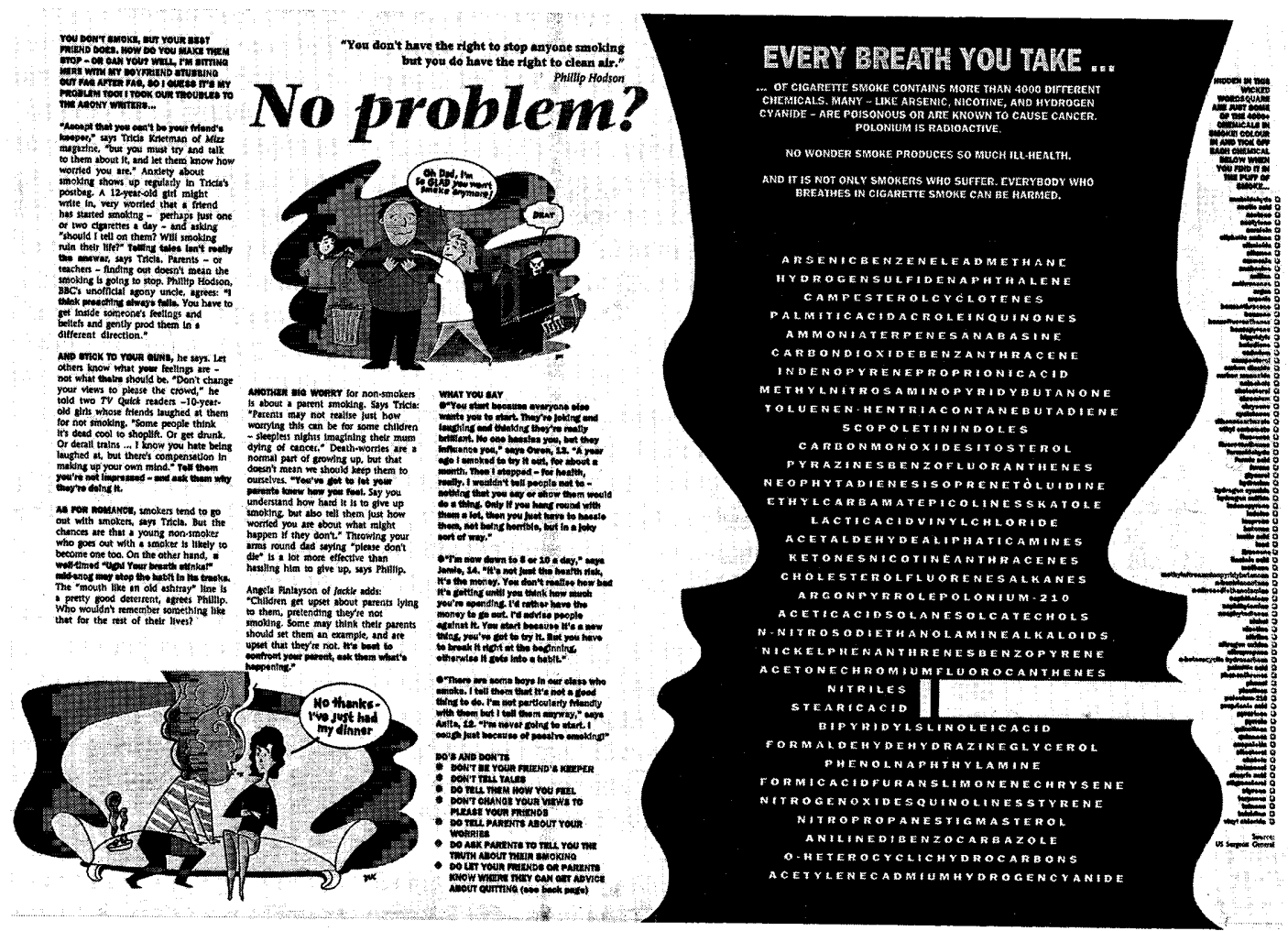
of smoke between two faces seen in profile. These faces derive from the well-known demonstration of gestalt shifts. Do we see two faces or do we see a vase? But there's another twist - the faces are not symmetrical. One person is smoking a cigarette; the other is backing away (figure 2).

Do children "get" all the jokes and allusions we cram in? Probably not, but does this matter? As Graham Higgins says, comics are like buses. You can miss one, but there's always another coming along behind. As it happens, our experience is that children are highly visually literate - in some ways more so than their parents - and relish all kinds of playful absurdity, pun and paradox. That's what they find in the best comics, and that's what we try to include in all Comic Company resources.

\section{Note to readers}

We hereby solicit your ideas and contributions for future covers of Tobacco Control. Like previous covers, we would like future covers to be colourful and creative - with a tobacco control theme. Original artwork, anti-tobacco posters, photographs, and cartoons may all be considered. Material with an international flavour would be particularly desirable. A cover essay will generally appear in each issue to provide appropriate background information and commentary on the cover.

Please send ideas and submissions (originals or high-quality, camera-ready photographs) to the editor at the address on the inside front cover.- ED

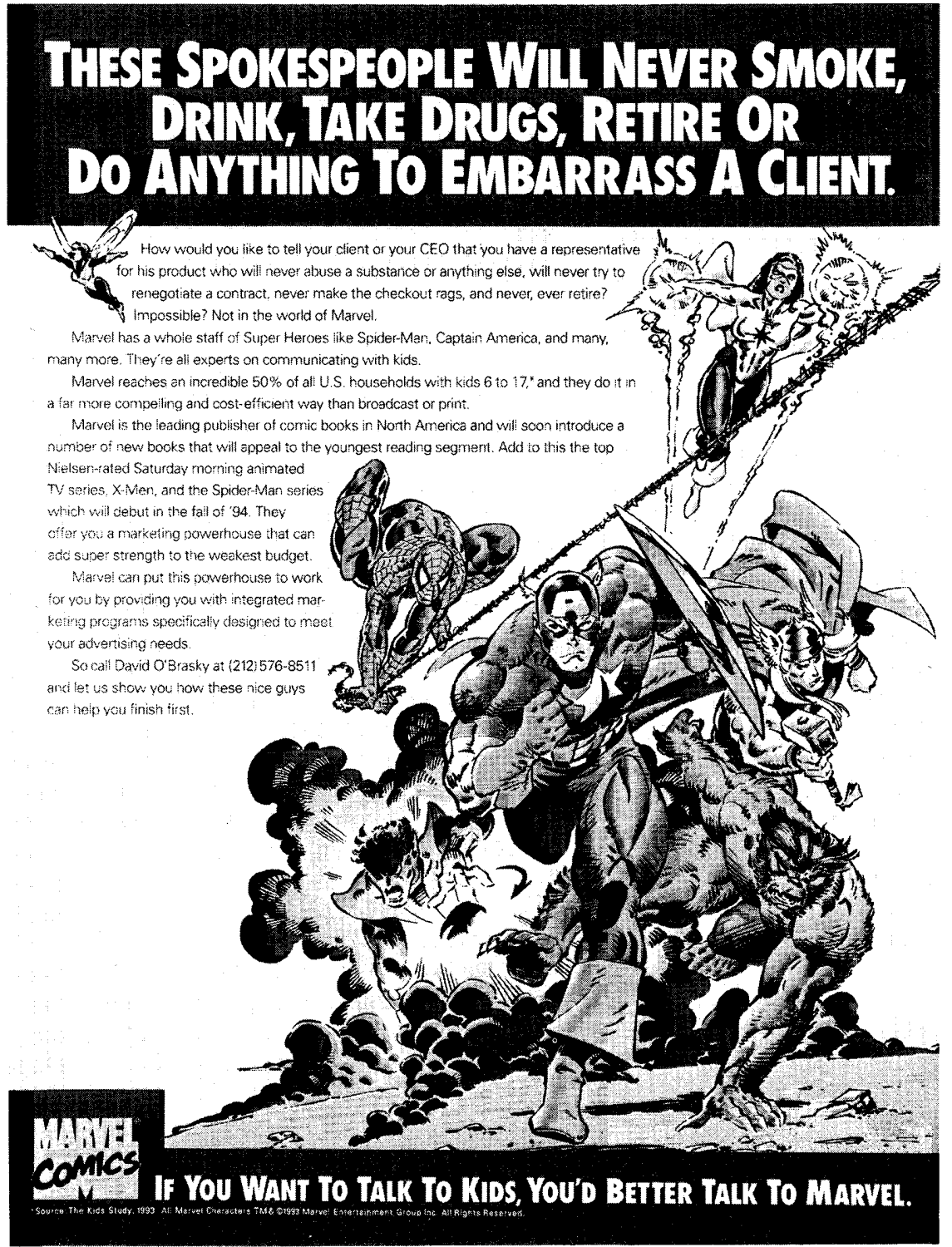

Marvel Comics seeks advertisers with the pitch that its Superhero spokespeople "will never smoke... or do anything to embarrass a client" (Advertising Age, 14 February 1994). Marvel did have characters (villains and heroes) smoking on some of its trading cards, but ended the practice in response to a letter to the editor published in $\mathrm{N}$ Engl J Med (1994; 330:1321) from Sammy Blum, aged 7. 